\title{
Key Points from the Updated Guidelines on Exercise and Diabetes
}

\author{
Sheri R. Colberg* \\ Human Movement Sciences Department, Old Dominion University, Norfolk, VA, USA
}

Keywords: physical activity, exercise, diabetes, guidelines, American Diabetes Association

\section{INTRODUCTION}

No doubt remains that the adoption and maintenance of physical activity is important for overall health and blood glucose management in individuals with diabetes and prediabetes. Recently, the American Diabetes Association (ADA) published updated recommendations and precautions about physical activity and exercise in people with type 1 diabetes, type 2 diabetes, and gestational diabetes (1). Given the importance of these topics, it is worth discussing the key changes and updates included in this ADA position statement (PS).

\section{Pre-Exercise Health Screening and Evaluation}

This PS reiterates that "pre-exercise medical clearance is not necessary for asymptomatic, sedentary individuals who wish to begin low- or moderate-intensity physical activity not exceeding the demands of brisk walking or everyday living" (1). This stance directly opposes a recent recommendation from

OPEN ACCESS

Edited by:

Jonathan Peter Little,

University of British Columbia,

Canada

Reviewed by:

Normand Boule,

University of Alberta, Canada Jamie F. Burr,

University of Guelph, Canada

${ }^{*}$ Correspondence:

Sheri R. Colberg

scolberg@odu.edu

Specialty section:

This article was submitted to Diabetes, a section of the journal

Frontiers in Endocrinology

Received: 14 January 2017 Accepted: 07 February 2017 Published: 20 February 2017

Citation:

Colberg SR (2017) Key Points from the Updated Guidelines

on Exercise and Diabetes.

Front. Endocrinol. 8:33. doi: 10.3389/fendo.2017.00033 the American College of Sports Medicine (ACSM) (2) that requires anyone with a metabolic disease (in this case, diabetes) who desires to begin exercising at any level-even doing light activities-to obtain medical clearance from a health-care provider first. The authors of the ADA PS did not agree with this restriction and took the same stance as the prior ADA PS on type 2 diabetes and exercise (3), which I believe is a much better recommendation. Making adults obtain any type of medical clearance prior to starting walking, for example, is an unnecessary barrier that will not necessarily make exercising any safer for them. However, ADA agrees with ACSM that adults with diabetes who plan to exercise at higher intensities than currently undertaken or who would be considered at high risk for cardiovascular disease (e.g., have elevated blood cholesterol, smoke, have a strong family history, etc.) or other health complications from doing such activities are recommended to obtain a pre-training examination from a health-care provider who may or may not recommend exercise stress testing (3).

\section{RECOMMENDED PHYSICAL ACTIVITY/EXERCISE}

All physical movement has the potential to improve physical and mental health (4-6). Since blood glucose management varies with a number of factors, it is critical for recommendations to be tailored for activity type and health complications to be effective $(3,7)$. In the PS, physical activity is defined as any movement that increases energy use, and exercise is a subset of physical activity that is more planned or structured (1), which is an important distinction.

\section{Aerobic Exercise Training}

As previously recommended, most adults with type 1 or type 2 diabetes should undertake at least $150 \mathrm{~min}$ or more of moderate- to vigorous-intensity activity weekly; it is also recommended that these activities occur on at least 3 or more days during the week and that individuals should not allow more than 2 days to elapse between activity sessions to maintain higher levels of insulin sensitivity 
(Table 1). However, it is now recognized in this PS that younger or more physically fit individuals may receive similar cardiovascular and fitness benefits from undertaking vigorous-intensity or high-intensity interval training (HIIT), assuming it adds up to a minimum of $75 \mathrm{~min} /$ week $(1,8,9)$.

Also included in the PS this time for the first time is HIIT, which is a type of training that includes short bursts (seconds to minutes) of very intense activity with recovery periods interspersed that may involve a lower intensity activity or rest. Such training has been demonstrated to result in greater insulin sensitivity and better overall blood glucose levels, at least in adults with type 2 diabetes $(9,10)$. Adults with type 1 diabetes can engage in HIIT and manage blood glucose with appropriate regimen changes $(8,11)$, which may include more insulin during and following and activity and reduced dosing overnight, along with food intake to prevent overnight hypoglycemia. Since its safety and efficacy remain unclear for some adults $(12,13)$, individuals who undertake such training should be clinically stable, already exercising regularly in activities that are moderate in intensity or harder, and possibly supervised when HIIT is started (14). This type of training is definitely not right for everyone.

\section{Resistance Exercise Training}

The PS recommends 2-3 sessions/week of resistance exercise on non-consecutive days using a variety of strength training modalities (1), which is also unchanged from prior recommendations and from guidelines for all adults. Although heavier resistance training improves glycemic control and strength more than lighter weights or home-based activities (15), all resistance training has the potential to result in greater strength, which can translate into improved balance and ability to live independently and undertake activities of daily living.

The main PS update is related to discussing the glycemic impact of resistance exercise in adults with type 1 diabetes (1), which remains unclear (8). It may lower the risk of developing exercise-induced hypoglycemia in type 1 diabetes (16). When both aerobic and resistance exercise are undertaken during a solitary activity session, it has been shown that doing the bout of resistance work first may actually help maintain glycemic balance more so than when aerobic exercise occurs before resistance training (17). Varying the order of the activities based on blood glucose levels may minimize the risk of hypoglycemia.

\section{Flexibility and Balance Exercises}

One major change of this PS is a greater focus on the inclusion of flexibility exercise to improve range of motion around joints in individuals of all ages (18) and balance activities to improve gait and prevent falls in older adults (19). Both flexibility exercises and balance training are recommended to be done minimally 2-3 times/week, especially by older adults (1). Including both is vitally important to living well since limited joint mobility is common in older adults and long-standing diabetes due to advanced glycation end products formed by normal aging and hyperglycemia (20). Stretching increases range of motion around joints and flexibility (18), and balance training can reduce falls risk by improving balance and gait (19).

TABLE 1 | Exercise training recommendations.

\begin{tabular}{|c|c|c|c|}
\hline & Aerobic & Resistance & Flexibility and balance \\
\hline \multirow[t]{2}{*}{ Type of exercise } & $\begin{array}{l}\text { Prolonged, rhythmic activities using large muscle } \\
\text { groups (e.g., walking, cycling, and swimming) }\end{array}$ & $\begin{array}{l}\text { Resistance machines, free weights, resistance } \\
\text { bands, and/or body weight as resistance exercises }\end{array}$ & $\begin{array}{l}\text { Stretching: static, dynamic, and other } \\
\text { stretching, yoga }\end{array}$ \\
\hline & $\begin{array}{l}\text { May be done continuously or as high-intensity } \\
\text { interval training }\end{array}$ & & $\begin{array}{l}\text { Balance (for older adults): practice } \\
\text { standing on one leg, exercises using } \\
\text { balance equipment, lower-body and } \\
\text { core resistance exercises, tai chi }\end{array}$ \\
\hline \multirow[t]{2}{*}{ Intensity } & \multirow[t]{2}{*}{$\begin{array}{l}\text { Moderate to vigorous (subjectively experienced as } \\
\text { "moderate" to "very hard") }\end{array}$} & \multirow{2}{*}{$\begin{array}{l}\text { Moderate (e.g., } 15 \text { repetitions of an exercise that } \\
\text { can be repeated no more than } 15 \text { times) to vigorous } \\
\text { (e.g., } 6-8 \text { repetitions of an exercise that can be } \\
\text { repeated no more than } 6-8 \text { times) }\end{array}$} & $\begin{array}{l}\text { Stretch to the point of tightness or } \\
\text { slight discomfort }\end{array}$ \\
\hline & & & $\begin{array}{l}\text { Balance exercises light to moderate } \\
\text { intensity }\end{array}$ \\
\hline \multirow[t]{2}{*}{ Duration } & \multirow{2}{*}{$\begin{array}{l}\text { At least } 150 \mathrm{~min} / \text { week at moderate to vigorous } \\
\text { intensity for most adults with diabetes. For adults } \\
\text { able to run steadily at } 6 \mathrm{mph} / 9.7 \mathrm{kmph} \text { for } 25 \mathrm{~min} \text {, } \\
75 \mathrm{~min} / \text { week of vigorous activity may provide similar } \\
\text { cardioprotective and metabolic benefits }\end{array}$} & \multirow[t]{2}{*}{$\begin{array}{l}\text { At least } 8-10 \text { exercises with completion of } 1-3 \text { sets } \\
\text { of } 10-15 \text { repetitions to near fatigue per set on every } \\
\text { exercise early in training }\end{array}$} & $\begin{array}{l}\text { Hold static or do dynamic stretch } \\
\text { for } 10-30 \mathrm{~s} ; 2-4 \text { repetitions of each } \\
\text { exercise }\end{array}$ \\
\hline & & & Balance training can be any duration \\
\hline \multirow[t]{2}{*}{ Frequency } & \multirow{2}{*}{$\begin{array}{l}\text { 3-7 days/week, with no more than } 2 \text { consecutive } \\
\text { days without exercise }\end{array}$} & \multirow{2}{*}{$\begin{array}{l}\text { A minimum of } 2 \text { non-consecutive days/week, but } \\
\text { preferably } 3\end{array}$} & Flexibility: $\geq 2-3$ days/week \\
\hline & & & Balance: $\geq 2-3$ days/week \\
\hline Progression & $\begin{array}{l}\text { A greater emphasis should be placed on vigorous- } \\
\text { intensity aerobic exercise if fitness is a primary } \\
\text { goal of exercise and not contraindicated by } \\
\text { complications; both high-intensity interval and } \\
\text { continuous exercise training are appropriate activities } \\
\text { for most individuals with diabetes }\end{array}$ & $\begin{array}{l}\text { Beginning training intensity should be moderate, } \\
\text { involving 10-15 repetitions per set, with increases } \\
\text { in weight or resistance undertaken with a lower } \\
\text { number of repetitions (8-10) only after the target } \\
\text { number of repetitions per set can consistently be } \\
\text { exceeded; increase in resistance can be followed } \\
\text { by a greater number of sets and lastly by increased } \\
\text { training frequency }\end{array}$ & $\begin{array}{l}\text { Continue to work on flexibility and } \\
\text { balance training, increasing duration } \\
\text { and/or frequency to progress over time }\end{array}$ \\
\hline
\end{tabular}

Copyright $2016 \odot$ American Diabetes Association from Ref. (1). Reprinted with permission from The American Diabetes Association. 
Lower-body and core strengthening exercises may be considered part of balance training. Yoga may promote improvement in glycemic control, lipid levels, and body composition in adults with type 2 diabetes (21). Tai chi training may improve glycemic control and balance neuropathic symptoms and some dimensions of quality of life in adults with diabetes and neuropathy (22).

\section{Daily Movement}

Engaging in more unstructured daily activity, such as errands, household tasks, dog walking, and gardening, increases daily energy expenditure and assists with weight loss and maintenance (23-25). Increasing daily movement appears to acutely lower postprandial hyperglycemia and possibly improve blood glucose management, especially when undertaken after meals (26-34). It is recommended as part of a whole-day approach and as a starting place for anyone who is currently sedentary and either unwilling or unable to start engaging in more structured activities. For many deconditioned and older individuals with diabetes, increasing daily movement may be an appropriate place to start with physical activity rather than with more structured activities.

\section{Reduced Sedentary Time and Interrupted Sitting}

As demonstrated in adults with type 2 diabetes, encouraging them to interrupt prolonged periods of sitting with $15 \mathrm{~min}$ of walking after meals (26) and either light walking or simple bodyweight resistance activities undertaken for $3 \mathrm{~min}$ after every 30 min of inactivity (29) improves overall glycemic control. The PS recommends that all adults attempt to lower the total amount of time that they spend each day in sedentary activities and break up prolonged bouts of sitting with some type of light activity for a few minutes at least every $30 \mathrm{~min}$ to improve their glycemic management; both should be added to daily structured exercise and unstructured movement rather than being a replacement for them. Research in this area, however, is still in its infancyespecially in populations with diabetes-and more studies are needed to better define the best types and timing of activity, not only for managing blood glucose levels but also for preventing type 2 diabetes and reversing prediabetes in the first place.

\section{PHYSICAL ACTIVITY AND TYPE 2 DIABETES}

The impact of exercise on insulin action is transient and, accordingly, activities should be undertaken daily or no less frequently than every other day. It is important to continue to recommend that exercise be undertaken regularly since in many cases, acute effects of aerobic exercise may not last even $24 \mathrm{~h}$. At least one study has shown that if the same volume of exercise is doneeither as $30 \mathrm{~min}$ of moderate exercise daily or $1 \mathrm{~h}$ at the same intensity every other day-the glycemic effects over the ensuing 48-h period are similar (35). Exercise does not necessarily need to be prolonged to result in enhanced insulin sensitivity, but if shorter in duration, engaging in harder workouts or highintensity intervals will increase its impact $(36,37)$. However, daily moderate or high-intensity aerobic or resistance exercise is likely optimal (38-40). Aerobic training may improve overall glycemic control more than resistance training, but both reduce cardiovascular risk markers similarly (41), and a single bout of either may have a similar acute effect in any case (42). To achiever better glycemic management, engaging in combined aerobic and resistance training appears to be superior to undertaking either type of training on its own $(43,44)$. In fact, the PS states, "Adults should ideally perform both aerobic and resistance exercise training for optimal glycemic and health outcomes" (1), which I firmly believe to be an excellent recommendation.

It is also important for type 2 diabetic youth (children and adolescents) to be more physically active. Their goal should be to meet the activity goals recommended for all youth, which consists of $60 \mathrm{~min} /$ day or more of moderate- or vigorous-intensity aerobic activity, with vigorous, muscle-strengthening, and bonestrengthening activities at least 3 days/week (1). Few studies have been done to examine the impact of exercise training and interventions in youth with type 2 diabetes, and those are inconclusive, although it can be assumed that the health and glycemic benefits they would gain are similar to those experienced by adults with type 2 diabetes (45).

\section{PHYSICAL ACTIVITY AND TYPE 1 DIABETES}

This PS is the first in many decades to address the complexities of managing blood glucose with exercise in adults and children with type 1 diabetes (46). Both aerobic and resistance training are recommended for these adults (47-49), and youth with type 1 diabetes should follow general recommendations for children and adolescents (47). Blood glucose responses are impacted by the type, timing, intensity, and duration of exercise, as well as by many other factors. Different activities will likely require individualized adjustments to carbohydrate and food intake and insulin dosing during and after exercise.

Aerobic exercise after meals usually decreases blood glucose levels (50), especially during prolonged activity $(34,51,52)$. Doing activity during fasting conditions, however, results in more stable glycemia, with less of a decline or even a small increase in overall levels (53). Engaging in very intense activities either maintains or raises blood glucose $(16,54)$, depending on duration, which is an important point to keep in mind.

Variable glycemic responses to physical activity (46) make uniform recommendations nearly impossible. In general, individuals will need to increase their carbohydrate intake and/ or reduce circulating insulin levels when engaging in longer duration aerobic activities, along with frequently monitoring blood glucose. These additional recommendations are stated in the PS (1) but come from other studies: for low- to moderateintensity aerobic activities lasting 30-60 min during fasting or basal insulin conditions, $\sim 10-15 \mathrm{~g}$ of carbohydrate may suffice to prevent hypoglycemia (55). For activities done after bolus insulin, $30-60 \mathrm{~g}$ of carbohydrate per hour may be needed $(56,57)$, or insulin can be reduced $25-75 \%$ to reduce or eliminate the need for carbohydrate intake (58). Basal rate reductions for exercise may reduce hypoglycemia (59). 
Continuous glucose monitors (CGM) are more widely available nowadays and have increased in accuracy; for many individuals, wearing such a device may decrease the fear of developing exercise-induced hypoglycemia. They are able to provide blood glucose trends, which can potentially assist the user in preventing hypoglycemia or treating it sooner (60-63). Some issues with CGM use during activity remain, however, as stated in the PS (1): inadequate accuracy (64), sensor filament breakage $(62,63)$, inability to calibrate (61) time lags between the change in blood glucose and its detection by CGM (65), and variations in sensor performance (66-68). CGM devices are currently being paired with insulin pumps into closed-loop systems run by algorithms. These technological issues with CGM use during exercise are continuing to make regular participation in physical activity a huge hurdle to creating an effective system.

\section{PHYSICAL ACTIVITY AND PREGNANCY WITH DIABETES}

The PS recommends, "Females with pre-existing diabetes of any type should be advised to engage in regular physical activity prior to and during pregnancy" (1). It also reiterates prior recommendations from other organizations that state that "pregnant females with or at risk for gestational diabetes should engage in 20-30 min of moderate-intensity exercise on most or all days of the week" (69-71). Undertaking any type of training (aerobic or resistance) has the ability to improve insulin sensitivity and overall blood glucose management (72). Ideally, physical activity should start prior to pregnancy to reduce gestational diabetes risk (73) but can be initiated safely during pregnancy (69). Regular physical activity is important for other positive pregnancy outcomes as well and should be recommended to all females of childbearing age, both prior to and during pregnancy.

\section{MINIMIZING EXERCISE-RELATED ADVERSE EVENTS}

In the PS (1), it is reiterated that, "Exercise-induced hypoglycemia is common in type 1 diabetes, and to a lesser extent, people with type 2 diabetes using insulin or insulin secretagogues." Some medications (other than insulin) may increase exercise risk, and doses may need to be adjusted $(74,75)$. Given that fear of hypoglycemia related to exercise is a proven barrier to exercise participation (76), any strategies that will assist in minimizing its occurrence have the potential to increase adherence to exercise training. Other acute strategies to prevent hypoglycemia involve including short sprints, performing resistance exercise before aerobic exercise in the same session, and activity timing (77-82), which are primarily based on the ability of a greater release of counterregulatory hormones during intense activities to maintain blood glucose levels more effectively. Exercise-induced nocturnal hypoglycemia is a major concern (83). Hypoglycemic events occur typically within 6-15 h postexercise (84), although risk can extend out to $48 \mathrm{~h}$ (85). Risk of nocturnal hypoglycemia following physical activity may be mitigated with lower basal insulin doses overnight, bedtime snacks, and/or use of CGM, and these strategies should be recommended to assist in preventing delayed-onset lows.

Very intense exercise like sprinting (79), brief but intense aerobic exercise $(86)$, and heavy powerlifting $(87,88)$ may promote hyperglycemia, especially with elevated starting blood glucose levels (86). A number of strategies can mitigate exercise-induced hyperglycemia, though. For example, it may be modulated with insulin administration, interspersing moderate aerobic activity between intense bouts, and a low-intensity cooldown $(89,90)$. Another stance taken in the PS (1) is "Overconsumption of carbohydrates before or during exercise, along with aggressive insulin reduction, can promote hyperglycemia during any exercise (58). Exercising with hyperglycemia and elevated blood ketones is not recommended."

Aging combined with diabetes may result in worse blood glucose control; moreover, peripheral neuropathy may be present and skin blood flow and sweating impaired (91-93), which increases the risk of heat-related illness. Chronic hyperglycemia also causes dehydration. These are all fairly new findings. For these reasons, the PS (1) recommends, "Older adults with diabetes or anyone with autonomic neuropathy, cardiovascular complications, or pulmonary disease should avoid exercising outdoors on very hot and/or humid days to prevent heat-related illnesses."

In addition, these statements from the PS are aimed at avoidance of other exercise-related adverse responses (1), which is critical for continued participation: "Active individuals with type 1 diabetes are not at increased risk of tendon injury (94), but this may not apply to sedentary or older individuals with diabetes. Diabetes may lead to exercise-related overuse injuries due to changes in joint structures related to glycemic excursions (95), so exercise training should progress appropriately to avoid excessive aggravation to joint surfaces and structures, particularly when taking statin medications for lipid control (96)."

\section{MANAGING HEALTH COMPLICATIONS}

Finally, many individuals with diabetes carry the burden of having associated health concerns, many of which can impact their ability to exercise safely and effectively. None of these are new ideas, but here is a summary of recommended actions as stated in the PS (1): macrovascular and microvascular diabetesrelated complications can develop and worsen with inadequate blood glucose management $(97,98)$. Physical activity with vascular diseases can be undertaken safely, but with appropriate precautions. Being active with peripheral neuropathy necessitates proper foot care to prevent, detect, and treat problems early to avoid ulceration and amputation. Autonomic neuropathy may complicate being active; certain precautions are warranted to prevent problems during activity, such as avoiding rapid directional changes (if orthostatic hypotension is present) and preventing dehydration and overheating during exercise with adequate fluid intake. Vigorous aerobic or resistance exercise, jumping, jarring, and head-down activities, and breath-holding should be avoided in anyone with severe non-proliferative and unstable proliferative diabetic retinopathy. Exercise with diabetic kidney disease can be undertaken safely, even during dialysis sessions. Regular 
stretching and appropriate progression of activities should be done to manage joint changes and diabetes-related orthopedic limitations.

\section{CONCLUSION}

This PS really does not contain any controversial recommendations, other than ADA disagreeing (strongly) with the requirement that ACSM put forth that all individuals with a metabolic condition who are currently sedentary must seek medical clearance prior to getting up off the couch. It is good to be reminded as well that although everyone can benefit from being physically active, specific recommendations and precautions will vary by the type of diabetes, age, activity done, and presence of complications, and exercise prescriptions should be tailored to meet the specific needs

\section{REFERENCES}

1. Colberg SR, Sigal RJ, Yardley JE, Riddell MC, Dunstan DW, Dempsey PC, et al. Physical activity/exercise and diabetes: a position statement of the American Diabetes Association. Diabetes Care (2016) 39:2065-79. doi:10.2337/ dc16-1728

2. Riebe D, Franklin BA, Thompson PD, Garber CE, Whitfield GP, Magal M, et al. Updating ACSM's recommendations for exercise preparticipation health screening. Med Sci Sports Exerc (2015) 47:2473-9. doi:10.1249/ MSS.0000000000000664

3. Colberg SR, Sigal RJ, Fernhall B, Regensteiner JG, Blissmer BJ, Rubin RR, et al. Exercise and type 2 diabetes: the American College of Sports Medicine and the American Diabetes Association: joint position statement. Diabetes Care (2010) 33:e147-67. doi:10.2337/dc10-9990

4. Chen L, Pei JH, Kuang J, Chen HM, Chen Z, Li ZW, et al. Effect of lifestyle intervention in patients with type 2 diabetes: a meta-analysis. Metabolism (2015) 64:338-47. doi:10.1016/j.metabol.2014.10.018

5. Lin X, Zhang X, Guo J, Roberts CK, McKenzie S, Wu WC, et al. Effects of exercise training on cardiorespiratory fitness and biomarkers of cardiometabolic health: a systematic review and meta-analysis of randomized controlled trials. J Am Heart Assoc (2015) 4:e002014. doi:10.1161/JAHA.115.002014

6. Yardley JE, Hay J, Abou-Setta AM, Marks SD, McGavock J. A systematic review and meta-analysis of exercise interventions in adults with type 1 diabetes. Diabetes Res Clin Pract (2014) 106:393-400. doi:10.1016/j.diabres.2014.09.038

7. American Diabetes Association. 4. Lifestyle management. Diabetes Care (2017) 40:S33-43. doi:10.2337/dc17-S007

8. Tonoli C, Heyman E, Roelands B, Buyse L, Cheung SS, Berthoin S, et al. Effects of different types of acute and chronic (training) exercise on glycaemic control in type 1 diabetes mellitus: a meta-analysis. Sports Med (2012) 42:1059-80. doi:10.2165/11635380-000000000-00000

9. Jelleyman C, Yates T, O’Donovan G, Gray LJ, King JA, Khunti K, et al. The effects of high-intensity interval training on glucose regulation and insulin resistance: a meta-analysis. Obes Rev (2015) 16:942-61. doi:10.1111/obr.12317

10. Little JP, Gillen JB, Percival ME, Safdar A, Tarnopolsky MA, Punthakee Z, et al. Low-volume high-intensity interval training reduces hyperglycemia and increases muscle mitochondrial capacity in patients with type 2 diabetes. J Appl Physiol (1985) 2011(111):1554-60.

11. Dube MC, Lavoie C, Weisnagel SJ. Glucose or intermittent high-intensity exercise in glargine/glulisine users with T1DM. Med Sci Sports Exerc (2013) 45:3-7. doi:10.1249/MSS.0b013e31826c6ad3

12. Biddle SJ, Batterham AM. High-intensity interval exercise training for public health: a big hit or shall we hit it on the head? Int J Behav Nutr Phys Act (2015) 12:95. doi:10.1186/s12966-015-0254-9

13. Mitranun W, Deerochanawong C, Tanaka H, Suksom D. Continuous vs interval training on glycemic control and macro- and microvascular reactivity in type 2 diabetic patients. Scand J Med Sci Sports (2014) 24:e69-76. doi:10.1111/sms.12112

14. Levinger I, Shaw CS, Stepto NK, Cassar S, McAinch AJ, Cheetham C, et al. What doesn't kill you makes you fitter: a systematic review of high-intensity of each individual. Overall, this ADA PS provides a comprehensive and current guide to assist individuals of all ages with any type of diabetes with engaging in recommended amounts of regular physical activity safely and effectively and is a much-needed publication. For even more specifics about type 1 diabetes and exercise participation, however, readers are referred to a very recent consensus statement (99) sponsored by the Juvenile Diabetes Research Foundation, which is far more comprehensive for this group of exercisers than this ADA PS ever intended to or realistically could be since it covered all types of diabetes, not just type 1 .

\section{AUTHOR CONTRIBUTIONS}

SC wrote and edited this opinion piece with no input from any other authors.

interval exercise for patients with cardiovascular and metabolic diseases. Clin Med Insights Cardiol (2015) 9:53-63. doi:10.4137/CMC.S26230

15. Willey KA, Singh MA. Battling insulin resistance in elderly obese people with type 2 diabetes: bring on the heavy weights. Diabetes Care (2003) 26:1580-8.

16. Yardley JE, Kenny GP, Perkins BA, Riddell MC, Balaa N, Malcolm J, et al. Resistance versus aerobic exercise: acute effects on glycemia in type 1 diabetes. Diabetes Care (2013) 36:537-42. doi:10.2337/dc12-0963

17. Yardley JE, Kenny GP, Perkins BA, Riddell MC, Malcolm J, Boulay P, et al. Effects of performing resistance exercise before versus after aerobic exercise on glycemia in type 1 diabetes. Diabetes Care (2012) 35:669-75. doi:10.2337/ dc11-1844

18. Herriott MT, Colberg SR, Parson HK, Nunnold T, Vinik AI. Effects of 8 weeks of flexibility and resistance training in older adults with type 2 diabetes. Diabetes Care (2004) 27:2988-9.

19. Morrison S, Colberg SR, Mariano M, Parson HK, Vinik AI. Balance training reduces falls risk in older individuals with type 2 diabetes. Diabetes Care (2010) 33:748-50. doi:10.2337/dc09-1699

20. Abate M, Schiavone C, Pelotti P, Salini V. Limited joint mobility in diabetes and ageing: recent advances in pathogenesis and therapy. Int J Immunopathol Pharmacol (2010) 23:997-1003.

21. Innes KE, Selfe TK. Yoga for adults with type 2 diabetes: a systematic review of controlled trials. JDiabetes Res (2016) 2016:6979370. doi: $10.1155 / 2016 / 6979370$

22. Ahn S, Song R. Effects of tai chi exercise on glucose control, neuropathy scores, balance, and quality of life in patients with type 2 diabetes and neuropathy. J Altern Complement Med (2012) 18:1172-8. doi:10.1089/acm.2011.0690

23. Levine JA, McCrady SK, Lanningham-Foster LM, Kane PH, Foster RC, Manohar CU. The role of free-living daily walking in human weight gain and obesity. Diabetes (2008) 57:548-54.

24. Levine JA, Lanningham-Foster LM, McCrady SK, Krizan AC, Olson LR, Kane $\mathrm{PH}$, et al. Interindividual variation in posture allocation: possible role in human obesity. Science (2005) 307:584-6.

25. Levine JA, Eberhardt NL, Jensen MD. Role of nonexercise activity thermogenesis in resistance to fat gain in humans. Science (1999) 283:212-4.

26. van Dijk JW, Venema M, van Mechelen W, Stehouwer CD, Hartgens F, van Loon LJ. Effect of moderate-intensity exercise versus activities of daily living on 24-hour blood glucose homeostasis in male patients with type 2 diabetes. Diabetes Care (2013) 36:3448-53. doi:10.2337/dc12-2620

27. Dunstan DW, Kingwell BA, Larsen R, Healy GN, Cerin E, Hamilton MT, et al. Breaking up prolonged sitting reduces postprandial glucose and insulin responses. Diabetes Care (2012) 35:976-83. doi:10.2337/dc11-1931

28. Henson J, Davies MJ, Bodicoat DH, Edwardson CL, Gill JM, Stensel DJ, et al. Breaking up prolonged sitting with standing or walking attenuates the postprandial metabolic response in postmenopausal women: a randomized acute study. Diabetes Care (2016) 39:130-8. doi:10.2337/dc15-1240

29. Dempsey PC, Larsen RN, Sethi P, Sacre JW, Straznicky NE, Cohen ND, et al. Benefits for type 2 diabetes of interrupting prolonged sitting with brief bouts of light walking or simple resistance activities. Diabetes Care (2016) 39:964-72. doi: $10.2337 / \mathrm{dc} 15-2336$ 
30. Larsen RN, Kingwell BA, Robinson C, Hammond L, Cerin E, Shaw JE, et al. Breaking up of prolonged sitting over three days sustains, but does not enhance, lowering of postprandial plasma glucose and insulin in overweight and obese adults. Clin Sci (Lond) (2015) 129:117-27. doi:10.1042/CS20140790

31. DiPietro L, Gribok A, Stevens MS, Hamm LF, Rumpler W. Three 15-min bouts of moderate postmeal walking significantly improves 24 -h glycemic control in older people at risk for impaired glucose tolerance. Diabetes Care (2013) 36:3262-8. doi:10.2337/dc13-0084

32. Nygaard H, Tomten SE, Hostmark AT. Slow postmeal walking reduces postprandial glycemia in middle-aged women. Appl Physiol Nutr Metab (2009) 34:1087-92. doi:10.1139/H09-110

33. Colberg SR, Zarrabi L, Bennington L, Nakave A, Thomas Somma C, Swain DP, et al. Postprandial walking is better for lowering the glycemic effect of dinner than pre-dinner exercise in type 2 diabetic individuals. J Am Med Dir Assoc (2009) 10:394-7. doi:10.1016/j.jamda.2009.03.015

34. Manohar C, Levine JA, Nandy DK, Saad A, Dalla Man C, McCrady-Spitzer SK, et al. The effect of walking on postprandial glycemic excursion in patients with type 1 diabetes and healthy people. Diabetes Care (2012) 35:2493-9. doi:10.2337/dc11-2381

35. van Dijk JW, Tummers K, Stehouwer CD, Hartgens F, van Loon LJ. Exercise therapy in type 2 diabetes: is daily exercise required to optimize glycemic control? Diabetes Care (2012) 35:948-54. doi:10.2337/dc11-2112

36. Gillen JB, Little JP, Punthakee Z, Tarnopolsky MA, Riddell MC, Gibala MJ. Acute high-intensity interval exercise reduces the postprandial glucose response and prevalence of hyperglycaemia in patients with type 2 diabetes. Diabetes Obes Metab (2012) 14:575-7. doi:10.1111/j.1463-1326.2012.01564.x

37. Manders RJ, Van Dijk JW, van Loon LJ. Low-intensity exercise reduces the prevalence of hyperglycemia in type 2 diabetes. Med Sci Sports Exerc (2010) 42:219-25. doi:10.1249/MSS.0b013e3181b3b16d

38. Hawley JA, Lessard SJ. Exercise training-induced improvements in insulin action. Acta Physiol (Oxf) (2008) 192:127-35.

39. Bacchi E, Negri C, Targher G, Faccioli N, Lanza M, Zoppini G, et al. Both resistance training and aerobic training reduce hepatic fat content in type 2 diabetic subjects with nonalcoholic fatty liver disease (the RAED2 Randomized Trial). Hepatology (2013) 58:1287-95. doi:10.1002/hep.26393

40. Snowling NJ, Hopkins WG. Effects of different modes of exercise training on glucose control and risk factors for complications in type 2 diabetic patients: a meta-analysis. Diabetes Care (2006) 29:2518-27.

41. Yang Z, Scott CA, Mao C, Tang J, Farmer AJ. Resistance exercise versus aerobic exercise for type 2 diabetes: a systematic review and meta-analysis. Sports Med (2014) 44:487-99. doi:10.1007/s40279-013-0128-8

42. van Dijk JW, Manders RJ, Tummers K, Bonomi AG, Stehouwer CD, Hartgens $\mathrm{F}$, et al. Both resistance- and endurance-type exercise reduce the prevalence of hyperglycaemia in individuals with impaired glucose tolerance and in insulin-treated and non-insulin-treated type 2 diabetic patients. Diabetologia (2012) 55:1273-82. doi:10.1007/s00125-011-2380-5

43. Church TS, Blair SN, Cocreham S, Johannsen N, Johnson W, Kramer K, et al. Effects of aerobic and resistance training on hemoglobin alc levels in patients with type 2 diabetes: a randomized controlled trial. JAMA (2010) 304:2253-62. doi:10.1001/jama.2010.1710

44. Sigal RJ, Kenny GP, Boule NG, Wells GA, Prud'homme D, Fortier M, et al. Effects of aerobic training, resistance training, or both on glycemic control in type 2 diabetes: a randomized trial. Ann Intern Med (2007) 147:357-69.

45. Today Study Group, Zeitler P, Hirst K, Pyle L, Linder B, Copeland K, et al. A clinical trial to maintain glycemic control in youth with type 2 diabetes. $N E n g l$ J Med (2012) 366:2247-56. doi:10.1056/NEJMoa1109333

46. Biankin SA, Jenkins AB, Campbell LV, Choi KL, Forrest QG, Chisholm DJ. Target-seeking behavior of plasma glucose with exercise in type 1 diabetes. Diabetes Care (2003) 26:297-301.

47. Physical Activity Guidelines Advisory Committee. Physical Activity Guidelines Advisory Committee Report, 2008. Washington, DC: U.S. Department of Health and Human Services (2008). 683 p.

48. MacMillan F, Kirk A, Mutrie N, Matthews L, Robertson K, Saunders DH. A systematic review of physical activity and sedentary behavior intervention studies in youth with type 1 diabetes: study characteristics, intervention design, and efficacy. Pediatr Diabetes (2014) 15:175-89. doi:10.1111/pedi.12060

49. Moy CS, Songer TJ, LaPorte RE, Dorman JS, Kriska AM, Orchard TJ, et al. Insulin-dependent diabetes mellitus, physical activity, and death. Am J Epidemiol (1993) 137:74-81.
50. Tansey MJ, Tsalikian E, Beck RW, Mauras N, Buckingham BA, Weinzimer $\mathrm{SA}$, et al. The effects of aerobic exercise on glucose and counterregulatory hormone concentrations in children with type 1 diabetes. Diabetes Care (2006) 29:20-5.

51. Mallad A, Hinshaw L, Schiavon M, Dalla Man C, Dadlani V, Basu R, et al. Exercise effects on postprandial glucose metabolism in type 1 diabetes: a triple-tracer approach. Am J Physiol Endocrinol Metab (2015) 308:E1106-15. doi:10.1152/ajpendo.00014.2015

52. Dube MC, Weisnagel SJ, Prud'homme D, Lavoie C. Is early and late post-meal exercise so different in type 1 diabetic lispro users? Diabetes Res Clin Pract (2006) 72:128-34.

53. Turner D, Luzio S, Gray BJ, Bain SC, Hanley S, Richards A, et al. Algorithm that delivers an individualized rapid-acting insulin dose after morning resistance exercise counters post-exercise hyperglycaemia in people with type 1 diabetes. Diabet Med (2016) 33:506-10. doi:10.1111/dme.12870

54. Mitchell TH, Abraham G, Schiffrin A, Leiter LA, Marliss EB. Hyperglycemia after intense exercise in IDDM subjects during continuous subcutaneous insulin infusion. Diabetes Care (1988) 11:311-7.

55. Riddell MC, Milliken J. Preventing exercise-induced hypoglycemia in type 1 diabetes using real-time continuous glucose monitoring and a new carbohydrate intake algorithm: an observational field study. Diabetes Technol Ther (2011) 13:819-25. doi:10.1089/dia.2011.0052

56. Francescato MP, Stel G, Stenner E, Geat M. Prolonged exercise in type 1 diabetes: performance of a customizable algorithm to estimate the carbohydrate supplements to minimize glycemic imbalances. PLoS One (2015) 10:e0125220. doi:10.1371/journal.pone.0125220

57. Adolfsson P, Mattsson S, Jendle J. Evaluation of glucose control when a new strategy of increased carbohydrate supply is implemented during prolonged physical exercise in type 1 diabetes. Eur J Appl Physiol (2015) 115:2599-607. doi:10.1007/s00421-015-3251-4

58. Campbell MD, Walker M, Bracken RM, Turner D, Stevenson EJ, Gonzalez JT, et al. Insulin therapy and dietary adjustments to normalize glycemia and prevent nocturnal hypoglycemia after evening exercise in type 1 diabetes: a randomized controlled trial. BMJ Open Diabetes Res Care (2015) 3:e000085. doi:10.1136/bmjdrc-2015-000085

59. Heinemann L, Nosek L, Kapitza C, Schweitzer MA, Krinelke L. Changes in basal insulin infusion rates with subcutaneous insulin infusion: time until a change in metabolic effect is induced in patients with type 1 diabetes. Diabetes Care (2009) 32:1437-9. doi:10.2337/dc09-0595

60. Yardley JE, Sigal RJ, Kenny GP, Riddell MC, Lovblom LE, Perkins BA. Point accuracy of interstitial continuous glucose monitoring during exercise in type 1 diabetes. Diabetes Technol Ther (2013) 15:46-9. doi:10.1089/dia.2012.0182

61. Bally L, Zueger T, Pasi N, Carlos C, Paganini D, Stettler C. Accuracy of continuous glucose monitoring during differing exercise conditions. Diabetes Res Clin Pract (2016) 112:1-5. doi:10.1016/j.diabres.2015.11.012

62. Fayolle C, Brun JF, Bringer J, Mercier J, Renard E. Accuracy of continuous subcutaneous glucose monitoring with the GlucoDay in type 1 diabetic patients treated by subcutaneous insulin infusion during exercise of low versus high intensity. Diabetes Metab (2006) 32:313-20.

63. Radermecker RP, Fayolle C, Brun JF, Bringer J, Renard E. Accuracy assessment of online glucose monitoring by a subcutaneous enzymatic glucose sensor during exercise in patients with type 1 diabetes treated by continuous subcutaneous insulin infusion. Diabetes Metab (2013) 39:258-62. doi:10.1016/j. diabet.2012.12.004

64. Herrington SJ, Gee DL, Dow SD, Monosky KA, Davis E, Pritchett KL. Comparison of glucose monitoring methods during steady-state exercise in women. Nutrients (2012) 4:1282-92. doi:10.3390/nu4091282

65. Iscoe KE, Davey RJ, Fournier PA. Is the response of continuous glucose monitors to physiological changes in blood glucose levels affected by sensor life? Diabetes Technol Ther (2012) 14:135-42. doi:10.1089/dia.2011.0194

66. Matuleviciene V, Joseph JI, Andelin M, Hirsch IB, Attvall S, Pivodic A, et al. A clinical trial of the accuracy and treatment experience of the Dexcom G4 sensor (Dexcom G4 system) and Enlite sensor (guardian real-time system) tested simultaneously in ambulatory patients with type 1 diabetes. Diabetes Technol Ther (2014) 16:759-67. doi:10.1089/dia.2014.0238

67. Kropff J, Bruttomesso D, Doll W, Farret A, Galasso S, Luijf YM, et al. Accuracy of two continuous glucose monitoring systems: a head-to-head comparison under clinical research centre and daily life conditions. Diabetes Obes Metab (2015) 17:343-9. doi:10.1111/dom.12378 
68. Leelarathna L, Nodale M, Allen JM, Elleri D, Kumareswaran K, Haidar A, et al. Evaluating the accuracy and large inaccuracy of two continuous glucose monitoring systems. Diabetes Technol Ther (2013) 15:143-9. doi:10.1089/ dia. 2012.0245

69. American College of Obstetrics and Gynecology. ACOG committee opinion no. 650: physical activity and exercise during pregnancy and the postpartum period. Obstet Gynecol (2015) 126:e135-42. doi:10.1097/ AOG.0000000000001214

70. Sanabria-Martinez G, Garcia-Hermoso A, Poyatos-Leon R, Alvarez-Bueno C, Sanchez-Lopez M, Martinez-Vizcaino V. Effectiveness of physical activity interventions on preventing gestational diabetes mellitus and excessive maternal weight gain: a meta-analysis. BJOG (2015) 122:1167-74. doi:10.1111/1471-0528.13429

71. Russo LM, Nobles C, Ertel KA, Chasan-Taber L, Whitcomb BW. Physical activity interventions in pregnancy and risk of gestational diabetes mellitus: a systematic review and meta-analysis. Obstet Gynecol (2015) 125:576-82. doi:10.1097/AOG.0000000000000691

72. Colberg SR, Castorino K, Jovanovic L. Prescribing physical activity to prevent and manage gestational diabetes. World J Diabetes (2013) 4:256-62. doi:10.4239/wjd.v4.i6.256

73. Zhang C, Solomon CG, Manson JE, Hu FB. A prospective study of pregravid physical activity and sedentary behaviors in relation to the risk for gestational diabetes mellitus. Arch Intern Med (2006) 166:543-8.

74. Larsen JJ, Dela F, Madsbad S, Vibe-Petersen J, Galbo H. Interaction of sulfonylureas and exercise on glucose homeostasis in type 2 diabetic patients. Diabetes Care (1999) 22:1647-54.

75. McDonnell ME. Combination therapy with new targets in type 2 diabetes: a review of available agents with a focus on pre-exercise adjustment. J Cardiopulm Rehabil Prev (2007) 27:193-201.

76. Brazeau AS, Rabasa-Lhoret R, Strychar I, Mircescu H. Barriers to physical activity among patients with type 1 diabetes. Diabetes Care (2008) 31:2108-9. doi:10.2337/dc08-0720

77. Bussau VA, Ferreira LD, Jones TW, Fournier PA. A 10-s sprint performed prior to moderate-intensity exercise prevents early post-exercise fall in glycaemia in individuals with type 1 diabetes. Diabetologia (2007) 50:1815-8.

78. Bussau VA, Ferreira LD, Jones TW, Fournier PA. The 10-s maximal sprint: a novel approach to counter an exercise-mediated fall in glycemia in individuals with type 1 diabetes. Diabetes Care (2006) 29:601-6.

79. Fahey AJ, Paramalingam N, Davey RJ, Davis EA, Jones TW, Fournier PA. The effect of a short sprint on postexercise whole-body glucose production and utilization rates in individuals with type 1 diabetes mellitus. J Clin Endocrinol Metab (2012) 97:4193-200. doi:10.1210/jc.2012-1604

80. Iscoe KE, Riddell MC. Continuous moderate-intensity exercise with or without intermittent high-intensity work: effects on acute and late glycaemia in athletes with type 1 diabetes mellitus. Diabet Med (2011) 28:824-32. doi:10.1111/j.1464-5491.2011.03274.x

81. Maran A, Pavan P, Bonsembiante B, Brugin E, Ermolao A, Avogaro A, et al. Continuous glucose monitoring reveals delayed nocturnal hypoglycemia after intermittent high-intensity exercise in nontrained patients with type 1 diabetes. Diabetes Technol Ther (2010) 12:763-8. doi:10.1089/dia.2010.0038

82. Campbell MD, West DJ, Bain SC, Kingsley MI, Foley P, Kilduff L, et al. Simulated games activity vs continuous running exercise: a novel comparison of the glycemic and metabolic responses in T1DM patients. Scand J Med Sci Sports (2015) 25:216-22. doi:10.1111/sms.12192

83. Frier BM. Hypoglycaemia in diabetes mellitus: epidemiology and clinical implications. Nat Rev Endocrinol (2014) 10:711-22. doi:10.1038/nrendo.2014.170

84. Tsalikian E, Mauras N, Beck RW, Tamborlane WV, Janz KF, Chase HP, et al. Impact of exercise on overnight glycemic control in children with type 1 diabetes mellitus. J Pediatr (2005) 147:528-34.
85. MacDonald MJ. Postexercise late-onset hypoglycemia in insulin-dependent diabetic patients. Diabetes Care (1987) 10:584-8.

86. Marliss EB, Vranic M. Intense exercise has unique effects on both insulin release and its roles in glucoregulation: implications for diabetes. Diabetes (2002) 51(Suppl 1):S271-83.

87. Turner D, Gray BJ, Luzio S, Dunseath G, Bain SC, Hanley S, et al. Similar magnitude of post-exercise hyperglycemia despite manipulating resistance exercise intensity in type 1 diabetes individuals. Scand J Med Sci Sports (2016) 26:404-12. doi:10.1111/sms.12472

88. Turner D, Luzio S, Gray BJ, Dunseath G, Rees ED, Kilduff LP, et al. Impact of single and multiple sets of resistance exercise in type 1 diabetes. Scand J Med Sci Sports (2015) 25:e99-109. doi:10.1111/sms.12202

89. Guelfi KJ, Jones TW, Fournier PA. The decline in blood glucose levels is less with intermittent high-intensity compared with moderate exercise in individuals with type 1 diabetes. Diabetes Care (2005) 28:1289-94.

90. Guelfi KJ, Ratnam N, Smythe GA, Jones TW, Fournier PA. Effect of intermittent high-intensity compared with continuous moderate exercise on glucose production and utilization in individuals with type 1 diabetes. Am J Physiol Endocrinol Metab (2007) 292:E865-70.

91. Yardley JE, Stapleton JM, Carter MR, Sigal RJ, Kenny GP. Is whole-body thermoregulatory function impaired in type 1 diabetes mellitus? Curr Diabetes Rev (2013) 9:126-36

92. Carter MR, McGinn R, Barrera-Ramirez J, Sigal RJ, Kenny GP. Impairments in local heat loss in type 1 diabetes during exercise in the heat. Med Sci Sports Exerc (2014) 46:2224-33. doi:10.1249/MSS.0000000000000350

93. Yardley JE, Stapleton JM, Sigal RJ, Kenny GP. Do heat events pose a greater health risk for individuals with type 2 diabetes? Diabetes Technol Ther (2013) 15:520-9. doi:10.1089/dia.2012.0324

94. Wong AM, Docking SI, Cook JL, Gaida JE. Does type 1 diabetes mellitus affect Achilles tendon response to a $10 \mathrm{~km}$ run? A case control study. $B M C$ Musculoskelet Disord (2015) 16:345. doi:10.1186/s12891-015-0803-z

95. Ranger TA, Wong AM, Cook JL, Gaida JE. Is there an association between tendinopathy and diabetes mellitus? A systematic review with meta-analysis. Br J Sports Med (2016) 50(16):982-9. doi:10.1136/bjsports-2015094735

96. de Oliveira LP, Vieira CP, Guerra FD, Almeida MS, Pimentel ER. Structural and biomechanical changes in the Achilles tendon after chronic treatment with statins. Food Chem Toxicol (2015) 77:50-7. doi:10.1016/j.fct.2014. 12.014

97. American Diabetes Association. 9. Cardiovascular disease and risk management. Diabetes Care (2017) 40:S75-87. doi:10.2337/dc17-S012

98. American Diabetes Association. 10. Microvascular complications and foot care. Diabetes Care (2017) 40:S88-98. doi:10.2337/dc17-S013

99. Riddell MC, Gallen IW, Smart CE, Taplin CE, Adolfsson P, Lumb AN, et al. Exercise management in type 1 diabetes: a consensus statement. Lancet Diabetes Endocrinol (2017) S2213-8587(17):30014-30011. doi:10.1016/ S2213-8587(17)30014-1

Conflict of Interest Statement: The author declares that the research was conducted in the absence of any commercial or financial relationships that could be construed as a potential conflict of interest.

Copyright (c) 2017 Colberg. This is an open-access article distributed under the terms of the Creative Commons Attribution License (CC BY). The use, distribution or reproduction in other forums is permitted, provided the original author(s) or licensor are credited and that the original publication in this journal is cited, in accordance with accepted academic practice. No use, distribution or reproduction is permitted which does not comply with these terms. 